\title{
Analisis Pengembangan Kurikulum Bahasa Arab di MTS Surya Buana Kota Malang
}

\author{
Imamuddin $^{1}$, Nuraidah $^{2}$, Miftahul Huda $^{3}$, Slamet Daroini $^{4}$ \\ ${ }^{1,2,3,4}$ Universitas Islam Negeri Maulana Malik Ibrahim Malang \\ E-mail: ${ }^{1}$ imamsape96@gmail.com, ${ }^{2}$ nuraidahsahrul@gmail.com, ${ }^{3}$ hudarhoma@yahoo.com, \\ 녹et_jatim@yahoo.com
}

\begin{abstract}
Abstrak : Sering dengan pergantian menteri pendidikan maka berganti pulalah kurikulum pendidikannya. Kurikulum tidak luput dari perombakan kurikulum sebelumnya hingga pada kurikulum 2013 saat ini. Akibat perubahan kurikulum tersebut, mata pelajaran bahasa Arab ikut terkena imbasnya. Begitu pula evaluasai dari kurikulum dari bahasa Arab tersebut. Tujuan penelitian ini untuk mengetahui pelaksanaan kurikulum bahasa Arab berupa visi misi dan tujuan, materi, metode, media, pendekatan, sumber, serta evaluasi kurikulum yang digunakan. Penelitian ini menggunakan penelitian kualitatif dengan desain deskriptif. Teknik pengumpulan datanya menggunakan wawancara, observasi, dan dokumentasi. Teknik analisis datanya menggunakan reduksi data, paparan data, dan kesimpulan atau verifikasi. Pengecekan keabsahan data menggunakan triangulasi, perpanjangan keikutsertaan, dan ketekunan pengamatan. Hasil penelitiannya yaitu ada keterkaitan yang sangat erat antara Visi, Misi dan Tujuan di MTS Surya Buana dengan Kurikulum 2013 yang diberlakukan oleh pemerintah saat ini, pelaksanaan kurikulum bahasa Arab menggunakan kurikulum 2013 dengan pendekatan seintifik dan disesuaikan dengan KI dan KD nya, metode yang diterapkan terbagi menjadi metode umum dan khusus, media yang digunakan beragam, dan evaluasi pembelajaran mencakup 4 komponen pokok yaitu spiritual, sosial, pengetahuan, dan keterampilan.
\end{abstract}

\begin{abstract}
Often with the change of the minister of education, the education curriculum changes. The curriculum did not escape from the previous curriculum reshuffle to the current 2013 curriculum. As a result of the curriculum change, Arabic subjects were also affected. Likewise the evaluation of the curriculum from the Arabic language. The purpose of this study was to determine the implementation of the Arabic language curriculum in the form of vision, mission and objectives, materials, methods, media, approaches, sources, and evaluation of the curriculum used. This study uses qualitative research with a descriptive design. Data collection techniques using interviews, observation, and documentation. The data analysis technique uses data reduction, data exposure, and conclusions or verification. Checking the validity of the data using triangulation, an extension of participation, and persistence of observations. The results of the research are that there is a very close relationship between the Vision, Mission and Goals at MTS Surya Buana with the 2013 Curriculum imposed by the current government, the implementation of the Arabic language curriculum uses the 2013 curriculum with an intuitive approach and is adapted to its KI and KD, the methods applied are divided into general and specific methods, the media used are varied, and the evaluation of learning includes 4 main components, namely spiritual, social, knowledge, and skill.
\end{abstract}

Kata kunci: Bahasa Arab; Kurikulum; Pengembangan 


\section{PENDAHULUAN}

Pergantian kurikulum seiring dengan pergantian menteri pendidikan merupakan agenda yang lazim di Indonesia. Sejak era Orde Lama hingga era Orde Baru, sudah beberapa kali kurikulum mengalami revisi, perubahan, atau penataan. ${ }^{1}$ Kurikulum tidak luput dari perombakan, sebut saja Kurikulum Berbasis Kompetensi (KBK) tahun 2004, Kurikulum Tingkat Satuan Pendidikan (KTSP) tahun 2006, dan yang telah diuji coba dan diterapkan pada saat ini, yaitu Kurikulum 2013 (K.13). ${ }^{2}$ Karena perubahan kurikulum tersebut, berdampak pula pada kurikulum mata pelajaran bahasa Arab. Dalam artian, seluruh perangkat pembelajaran bahasa Arab harus mengacu kepada kurikulum yang berlaku saat ini. $^{3}$

Oleh karena itu, proses pembelajaran bahasa Arab di sekolah-sekolah saat ini menggunakan kurikulum baru yang disebut Kurikulum 2013 tersebut. Kurikulum 2013 ini diberlakukan secara bertahap mulai Tahun Pelajaran 2013-2014 melalui pelaksanaan yang terbatas, khususnya bagi sekolah-sekolah yang sudah siap melaksanakannya. Pada Tahun Pelajaran 2013/2014, Kurikulum 2013 dilaksanakan secara terbatas untuk Kelas I dan IV Sekolah Dasar/Madrasah Ibtidaiyah (SD/MI), Kelas VII Sekolah Menengah Pertama / Madrasah Tsanawiyah (SMP/ MTs), dan Kelas X Sekolah Menengah Atas / Sekolah Menengah Kejuruan / Madrasah Aliyah (SMA/SMK/MA/MAK). Pada Tahun Pelajaran 2014/2015 diharapkan Kurikulum 2013 telah dilaksanakan di seluruh kelas I sampai dengan Kelas XII. ${ }^{4}$

Diterapkannya kurikulum 2013 ini banyak terjadi penyimpangan penyimpangan yang dilakukan sekolah karena belum siapnya sekolah menerapkan hal tersebut, tidak hanya materi, tetapi juga kemampuan SDM dari guru tersebut. Akhirnya penerapan kurikulum 2013 terkesan seadanya saja, hanya untuk mengikuti aturan dari pemerintah pusat. ${ }^{5}$

Banyak sekali faktor yang mempengaruhi keberhasilan pelaksanaan kurikulum dimadrasah, mulai dari, kompetensi guru/kepala sekolah, pengalaman guru/kepala sekolah (masa kerja), tingkat pendidikan guru/kepala sekolah, komitmen guru/kepala sekolah,dukungan komite sekolah, kelengkapan saran dan dan prasarana (laboratorium, perpustakaan,lapangan olahraga, sumber belajar), kebijakan kepala sekolah, dukungan anggaran, infrastruktur kurikulum itu sendiri, dukungan orang tua wali murid, kualitas input (siswa), dan dukungan stakeholders lainnya. ${ }^{6}$

Setelah dilaksanakan atau diimplementasikannya kurikulum tersebut maka perlulah diadakan analisis terhadap penggunaan kurikulum 2013 tersebut. Evaluasi kurikulum ini bertujuan untuk mengetahui apakah kurikulum yang telah diterapkan atau diimplementasikan sudah mencapai sasaran secara efektif atau belum, dan apakah kurikulum tersebut terlaksana sebagaimana mestinya atau belum. ${ }^{7}$ Setiap lembaga pendidikan dapat

\footnotetext{
${ }^{1}$ Siskandar, Evaluasi Implementasi Kurikulum 2013 di Madrasah Aliyah, dalam Jurnal Cendekia, Vol 10, No. 2, (Surakarta : Pusat Kajian Bahasa dan Budaya, 2016), h. 119

${ }^{2}$ Muhammad Zaini, Pengembangan Kurikulum Konsep Implementasi Evaluasi dan Inovasi, (Yogyakarta : Teras, 2009), h. 149

${ }^{3}$ Sofan Amri, Pengembangan dan Model Pembelajaran Dalam Kurikulum 2013, (Jakarta : Prestasi Pustaka, 2013), h. 51

${ }^{4}$ Azkia Muharom Al-bantani, Implementasi Kurikulum 2013Pada Pembelajaran Bahasa Arab Di Madrasah Ibtidaiyah, dalam Jurnal Arabiyat, Vol 2 No. 2, (Jakarta : UIN Jakarta, 2015), h. 179-180

${ }^{5}$ Muhammad Zulkifli, Analisis Bentuk Evaluasi Kurikulum 2013 Mata Pelajaran Bahasa Arab Di MI, dalam Jurnal Al-Madrasah, Vol. 2, No. 2, (Kalimantan Selatan : STIQ Amuntai, 2018), h. 127

${ }^{6}$ Teguh Triwiyanto, Manajemen Kurikulum dan Pembelajaran, (Jakarta : Bumi Aksara, 2015), h. 183

${ }^{7}$ Nana Syaodih Sukmadinata, Pengembangan Kurikulum : Teori dan Praktek, (Bandung : Remaja Rosdakarya, 2006), h. 172
} 
dipastikan memiliki analisis kurikulum sendiri dalam melihat sejauh mana kurikulum yang telah diterapkan dalam lembaga tersebut. Begitu pula lembaga MTS Surya Buana Kota Malang. ${ }^{8}$

Alasan peneliti memilih MTS Surya Buana Kota Malang. sebagai tempat penelitian kerena lembaga ini merupakan salah satu lembaga pendidikan Islam yang fokus pada program pembelajaran bahasa Arab dan pendidikan agama Islam. Lembaga ini juga sangat aktif dalam mengembangkan atau mengevaluasi kurikulum bahasa Arab yang telah diterapkannya, Sehingga pelaksanaan kurikulum bahasa Arab di MTS Surya Buana Kota Malang ini sangat perlu untuk dikaji lebih detail. Berdasarkan paparan di atas, peneliti tertarik untuk meneliti kurikulum bahasa Arab di lembaga tersebut. Oleh karena itu, dalam artikel ini peneliti akan menganalisis mengenai Visi misi dan tujuan, materi, metode, media, pendekatan, sumber belajar, serta evaluasi pembelajaran bahasa Arab di lembaga tersebut.

\section{METODE}

Penelitian ini merupakan penelitian lapangan di MTS Surya Buana Kota Malang. Penelitian ini bersifat deskriptif analitik ${ }^{9}$, yakni menggambarkan terkait pengembangan kurikulum bahasa Arab berbasis kurikulum 2013, serta menganalisis bentuk-bentuk implementasi tersebut dalam pembelajaran.

Sumber data dalam penelitian ini terbagi dalam dua kelompok yaitu sumber data primer dan sumber data sekunder ${ }^{10}$, dalam hal ini yang dimaksud sumber data primer adalah informan penelitian. Adapun informan yang terkait dalam objek penelitian ini adalah guru pengampu mata pelajaran bahasa Arab dan wakil kepala madrasah bidang kurikulum. Selanjutnya sumber data sekunder merupakan sebagai pendukung, diantaranya siswa, datadata perangkat pembelajaran tahun ajaran 2019-2020 seperti silabus dan rencana pelaksanaan pembelajaran (RPP).

Data penelitian didapatkan dengan beberapa teknik, yaitu wawancara terstruktur yang dilakukan untuk memperoleh kedalaman informasi terkait pengembangan kurikulum dengan sumber data primer $^{11}$, sedangkan wawancara semi terstruktur dilaksanakan agar peneliti menemukan jawaban permasalahan secara lebih terbuka, dengan sumber datanya yaitu siswa. Dalam hal ini peneliti menggunakan instrumen pedoman wawancara, catatan peneliti, alat tulis, dan perekam. Kemudian angket digunakan untuk pengecekan terhadap proses pembelajaran bahasa Arab di MTS Surya Buana.

\section{HASIL DAN PEMBAHASAN}

\section{A. Analisis Visi, Misi dan Tujuan}

1. Visi

Unggul dalam prestasi, Terdepan dalam Inovasi, Maju dalam Kreasi, Berwawasan Lingkungan, Berakhlakul Karimah ${ }^{12}$

2. Misi

1.) Membentuk perilaku berprestasi, pola pikir yang kritis dan kreatif pada siswa.

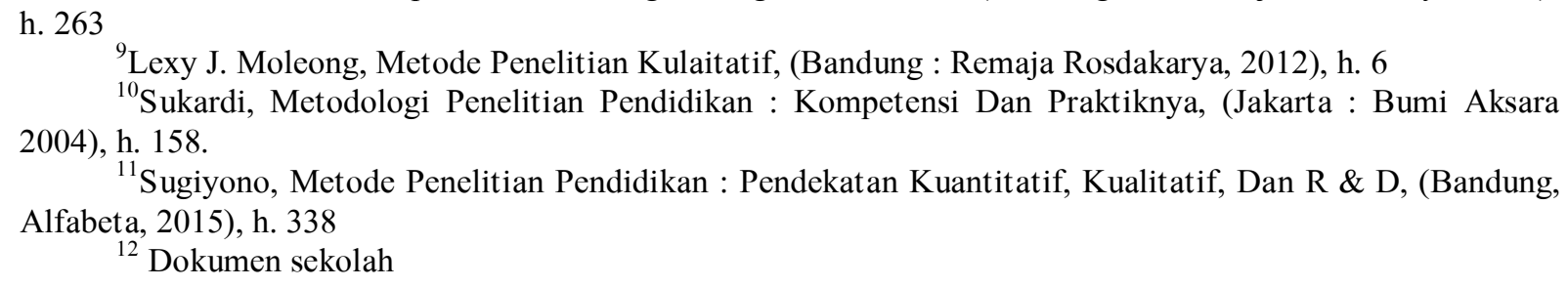

${ }^{10}$ Sukardi, Metodologi Penelitian Pendidikan : Kompetensi Dan Praktiknya, (Jakarta : Bumi Aksara 2004), h. 158.

${ }^{11}$ Sugiyono, Metode Penelitian Pendidikan : Pendekatan Kuantitatif, Kualitatif, Dan R \& D, (Bandung, Alfabeta, 2015), h. 338

${ }^{12}$ Dokumen sekolah 
2.) Mengembangkan pola pembelajaran yang inovatif dan tradisi berpikir ilmiah didasari oleh kemantapan penghayatan dan pengalaman nilai-nilai agama islam.

3.) Menumbuhkembangkan sikap kreatif, disiplin, dan bertanggungjawab serta penghayatan dan pengamalan nilai-nilai agama islam untuk membentuk siswa berakhlakul karimah.

4.) Membentuk siswa yang berwawasan lingkungan. ${ }^{13}$

3. Tujuan

1.) Memperoleh prestasi yang baik

2.) Membentuk siswa menjadi cendekiawan muslim yang menguasai ilmu pengetahuan, teknologi, seni, berakhlakul karimah

3.) Membentuk pola pengajaran yang dapat mengaktifkan dan melibatkan siswa secara maksimal

4.) Membentuk kegiatan yang dapat membangun kreativitas individu siswa

5.) Membentuk lingkungan Islami yang kondusif bagi siswa

6.) Membangun kompetisi berilmu, beramal, dan berfikir ilmiah

7.) Membentuk lingkungan Islami berwawasan ilmiah ${ }^{14}$

Setelah mengetahui Visi, Misi dan Tujuan MTS Surya Buana, maka dapat kita komparasikan dengan Visi, Misi dan Tujuan yang terdapat dalam kurikulum 2013. Adapun hasil perbandingan teori kurikulum 2013 dengan visi,misi, dan tujuan MTS Surya Buana sebagai berikut :

Dari segi visi ada kesesuaian yaitu melatih siswa untuk bersaing dalam sebuah prestasi, mendorong siswa untuk menjadi pelajar yang giat dan berwawasan luas. Dari misi ada kesesuaian yaitu Menyelenggarakan pendidikan yang bermutu, baik dari pembelajaran, yang dapat diaplikasikan pada akhlaqul karimah atau kepribadian siswa dalam berhubungan dengan masyarakat sekitar. Sedangkan dari segi tujuan ada kesesuaian yaitu Menitikberatkan siswa sebagai pribadi yang aktif, berkeyakinan terhadap Tuhan Yang Maha Esa sera dapat berinteraksi terhadap sesama. Dari pemaparan diatas dapat diambil sebuah kesimpulan bahwa ada keterkaitan yang sangat erat antara Visi, Misi dan Tujuan di MTS Surya Buana dengan Kurikulum 2013 yang diberlakukan oleh pemerintah saat ini.

\section{B. Analisis Materi}

Analisis materi meliputi: KI (Kompetensi Inti), KD (Kompetensi Dasar) serta keterkaitan antara keduannya, Materi Pembelajaran dan Analisis terakhir tentang Penilaian Pembelajaran. Pada pembahasan kali ini, materi yang yang dipelajari dalam pembelajaran Bahasa Arab kelas VII di MTS Surya Buana adalah : ${ }^{15}$

$$
\text { التعريف بالنفس وبالعاملين في المدرسة }
$$

Setelah kami menganalisa, maka dapat disimpulkan sebagai berikut:

\footnotetext{
${ }^{13}$ Dokumen sekolah

${ }^{14}$ Dokumen sekolah

${ }^{15}$ Buku pegangan guru bahasa Arab kelas VII
} 
"Ada keterkaitan antara K1 (Kompetensi Inti) dangan yang diturunkan pada KD (Kompetensi Dasar) dari beberapa tinjauan Sikap Religius, Sikap Sosial, Pengetahuan dan Ketrampilan". "Penjelasan ringkasnya sebagai berikut :

1.) Dari Sikap Religius yaitu Menghargai dan menghayati ajaran agama yang dianutnya. Kemudian diturunkan di KD (Kompetensi Dasar) menjadi Mensyukuri kesempatan dapat mempelajari bahasa Arab sebagai bahasa pengantar komunikasi internasional dan bahasa pengantar khazanah keislaman yang diwujudkan dalam semangat belajar.

2.) Dari Sikap Sosial yaitu Menghargai dan menghayati prilaku jujur, disiplin, tanggungjawab, peduli (toleransi,gotong royong), santun, percaya diri, dalam berinteraksi secara efektif dengan lingkungan sosial dan alam dalam jangkauan pergaulan dan keberadaannya. Kemudian diturunkan di KD menjadi:

a. Menunjukkan prilaku jujur dan percaya diri dalam berkomunikasi dengan lingkungan sosial sekitar rumah dan sekolah.

b. Menunjukkan prilaku motivasi internal (intrinsik) untuk pengembangan kemampuan berbahasa.

c. Menunjukkan sikap bertanggung jawab dalam mempraktikkan bahasa Arab sebagai bahasa komunikasi internasional dan pengantar dalam mengkaji khazanah keislaman.

3.) Dari Pengetahuan yaitu memahami pengetahuan (faktual, konseptual, dan prosedural) berdasarkan rasa ingin tahunya tentang ilmu pengetahuan, teknologi, seni, budaya terkait fenomena dan kejadian tampak mata. Kemudian diturunkan di KD menjadi:

a. Mengidentifikasi bunyi kata, frasa, dan kalimat bahasa Arab yang berkaitan dengan :

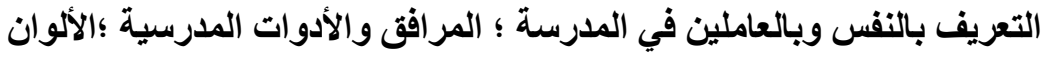

baik secara lisan maupun tertulis.

b. Melafalkan bunyi huruf, kata, frasa, dan kalimat bahasa Arab yang berkaitan dengan:

$$
\text { التعريف بالنفس وبالعاملين في المدرسة ؛ المرافق والأدوات المدرسية الألوان }
$$

c. Menemukan makna atau gagasan dari ujaran kata, frasa, dan kalimat bahasa Arab yang berkaitan dengan:

$$
\text { التعريف بالنفس وبالعاملين في المدرسة ؛ المرافق والأدوات المدرسية ؛ الألوان }
$$

4.) Dari keterampilan Mencoba, mengolah, dan menyaji dalam ranah kongkrit (menggunakan, mengurai, merangkai, memodifikasi, dan membuat) dan ranah abstrak (menulis, membaca, menghitung, menggambar, dan mengarang) sesuai dengan yang dipelajari di madrasah dan sumber lain yang sama dalam sudut pandang/teori. Kemudian diturunkan di KD menjadi:

a. Mendemonstrasikan ungkapan sederhana tentang topik

$$
\text { التعريف بالنفس وبالعاملين في المدرسة ؛ المرافق والأدوات المدرسية ؛ الألوان }
$$

dengan memperhatikan struktur teks dan unsur kebahasaan yang benar dan sesuai konteks

\footnotetext{
${ }^{16}$ Wawancara guru bahasa Arab
} 
b. Menunjukkan contoh ungkapan sederhana untuk menyatakan, menanyakan dan merespon tentang:

$$
\text { التعريف بالنفس وبالعاملين في المدرسة ؛ المرافق والأدوات المدرسية ؛ الألوان }
$$

dengan memperhatikan struktur teks dan unsur kebahasaan yang benar dan sesuai konteks

c. Menyampaikan berbagai informasi lisan sederhana tentang :

$$
\text { التعريف بالنفس وبالعاملين في المدرسة ؛ المرافق والأدوات المدرسية ؛ الألوان }
$$

d. Mengungkapkan informasi secara tertulis tentang :

$$
\text { التعريف بالنفس وبالعاملين في المدرسة ؛ المرافق والأدوات المدرسية ؛الألوان }
$$

dalam berbagai struktur bahasa sederhana secara tepat.

e. Menyusun teks sederhana tentang topik

$$
\text { التعريف بالنفس وبالعاملين في المدرسة ؛ المرافق والأدوات المدرسية ؛الألوان }
$$

dengan memperhatikan struktur teks dan unsur kebahasaan yang benar sesuai konteks

Berdasarkan analisa diatas maka dapat dikatakan bahwa kurikulum yang digunakan di MTS Surya Buana sesuai dengan kurikulum 2013, sebab point-point yang ada menitikberatkan pada pembelajaran berbasis karakter dan kompetensi yang mewajibkan anak untuk aktif dalam pembelajaran sebagaimana yang tercantum dalam pengertian serta tujuan Kurikulum 2013.

Selain itu juga pengertian kurikulum 2013 itu sendiri ialah, sebuah kurikulum yang terintegrasi, maksud dari integrasi ini adalah sebuah kurikulum yang mengintegrasikan Skill, Theme, Concepts, And Topic baik dalam bentuk Within Sigle disciplines, Acrous several disciplines and Within and Acrous Learners. Dengan kata lain bahwa kurikulum 2013 ialah kurikulum yang terpadu sebagai suatu konsep dapat dikatakan sebagai sebuah sistem atau pendekatan pembelajaran yang melibatkan beberapa disiplin ilmu untuk memberikan pengalaman yang bermakna dan luas kepada peserta didik.

Analisis berikutnya dari segi Materi Pembelajaran dalam RPP MTS surya Buana menerapkan pembelajaran mata pelajaran Bahasa Arab sudah sesuai dengan Maharah Lughawiyah yaitu Istima (Mendengarkan), Hiwar (Percakapan), Qiraah (Membaca) dan Kitabah (Menulis). ${ }^{17}$

Hal ini mendukung pembelajaran mata pelajaran Bahasa Arab, namun alokasi waktu yang diberikan oleh madrasah relatif sedikit yaitu dua kali pertemuan dalam satu minggu dan setiap pertemuannya berdurasi 40 menit.

Kemudian Analisis dari segi Penilaian Pembelajaran bahasa arab dalam RPP MTS Surya Buana sudah sesuai dengan kurikulum 2013 dikarenakan Setelah KKM (Kriteria Ketuntasan Minimal) ditentukan, capaian pembelajaran peserta didik dapat dievaluasi ketuntasannya. Peserta didik yang belum mencapai KKM berarti belum tuntas, wajib mengikuti program remedial, sedangkan peserta didik yang sudah mencapai KKM dinyatakan tuntas dan dapat diberikan pengayaan.

\footnotetext{
${ }^{17}$ Wawancara guru bahasa Arab
} 


\section{Metode, Media, dan Pendekatan}

Berdasarkan peraturan menteri pendidikan dan kebudayaan nomor 22 tahun 2016 tentang standar proses pendidikan dasar dan menengah bahwa dalam perencenaan harus mencantumkan metode dan media. ${ }^{18}$ Dalam suatu pembelajaran tentunya seorang pengajar tidak akan mencapai keberhasilan tanpa adanya metode-metode dan berbagai media yang menjadi pendukung disaat proses pembelajaran berlangsung, maka dari itu seorang pengajar di MTS Surya Buana menggunakan berbagai macam metode dan media sebagai pendukung keberhasilan disaat mengajar. Diantara metode dan media yang digunakan adalah :

\section{Metode Pembelajaran}

a. Metode umum

1.) Al-samiyah al-syafawiyah

Metode tersebut menekankan cara mengucapkan dan mengidentifikasi bunyi tersebut dengan cara guru terlebih dahulu menyebutkannyanya sedangkan siswa menyimak apa yang diucapakan gurunya lalu siswa dituntut untuk mengulanginya.

2.) Toriqoh mubasyaroh

Metode ini digunakan oleh seorang guru dalam proses belajar mengajar dimana seorang guru tidak menggunakan bahasa pertamanya dalam menjalaskan pelajaran , melainkan menggunakan bahasa kedua walaupun seorang pelajar mendapatkan kesulitan terhadap suatu kalimat yang disampaikan oleh seorang guru, akan tetapi seorang guru menggunakan bahasa isyarat dengan ekspresi wajah dan gerak gerik tangan atau menunjuk sesuatu agarseorang pelajar bisa memahami apa yang disampaikan oleh guru tersebut.

\section{3.) Toriqoh intoqoiyah}

Metode dimana seorang guru tidak cukup menggunakan satu metode saja dalam proses belajar mengajar karena terkadang ada yang sudah dipersiapkan tidak sesuai dengan keadaan dikelas oleh sebab itu seorang guru mengikut setakan toriqoh intiqoiyah.

b. Metode Khusus

1.) التعليم المتعاون dan karena metode ini sangat efektif untuk materi tersebut karena siswa dibentuk kelompok dengan kelompok yang berbeda, ada yang mendukung danada yang menolak sehingga kelompok tersebut sama-sama aktif dalam menyimak.

2.) عرض الصور dengan memberikan gambar sehingga dapat membantu siswa dalam menghafal mufrodat yang di dengar, yang selanjutnya dilatih untuk menambah kosa kata baru dengan menggunakan metode تعبير الكلمة الفييئية

\section{Media Pembelajaran}

"Media yang digunakan oleh guru sangat beragam, sesuai dengan kondisi atau kebutuhan siswa. Namun guru cenderung menggunakan media papan tulis dan Laptop "19

${ }^{18}$ Abu Bakar Muhamad, Metode Khusus Pengajaran Bahasa Arab, (Surabaya: Usaha Nasional, 1981), h. 8

${ }^{19}$ Wawancara dengan Wakil kepala sekolah bagian kurikulum 
Selain berbagai metode yang menjadi faktor pendukung keberhasilan siswa dalam suatu pembelajaran tentunya seorang guru itu mempunyai berbagai macam media yang digunakan dalam suatu pembelajar, bertujuan agar siswa itu senang terhadap apa yang dipelajarinya dan para siswa dikelas tersebut menjadi aktif dalam pembelajaran. Salah satu media yang digunakan guru dalam pembelajaran di MTS Surya Buana sebagai berikut: Laptop/ LCD.

\section{Pendekatan Pembelajaran}

Berdasarkan pada Rencana Pelaksanaan Pembelajaran (RPP), proses pembelajaran di MTS Surya Buana menggunakan pendekatan santifik. Yaitu mengamati, menanya, mengumpulkan informasi, mengasosiasi, dan mengkomunikasikan. Hal ini secara nyata tertulis dalam Peraturan menteri pendidikan dan kebudayaan NO 103 tentang pembelajaran pada pendidikan tingkat dasar dan menengah tahun 2014. Alokasi waktu yang dibutuhkan dalam pendekatan saintifik tersebut adalah 15 menit setelah sebelumnya dilakukan proses pendahuluan selama 10 menit oleh pengajar.

\section{Sumber Belajar}

Berdasarkan hasil analisa kami. Sumber belajar yang digunakan di MTS Surya Buana terdiri dari dua yaitu :

1. Buku guru bahasa arab VII

2. Buku siswa bahasa arab VII

Buku tersebut merupakan buku yang berdasarkan kurikulum 2013.

\section{E. Evaluasi}

Berdasarkan RPP maka proses evaluasi di MTS Surya Buana mencakup empat komponen yaitu evaluasi sikap spiritual, sosial, pengetahuan, dan keterampilan. Setiap komponen memiliki instrument penilaian. Evaluasi proses pembelajaran dilakukan saat proses pembelajaran dengan menggunakan alat : lembar observasi. Evaluasi hasil pembelajaran dilakukan saat proses pembelajaran dan diakhir satuan pelajaran dengan menggunakan metode dan alat : tes lisan. Hasil evaluasi akhir diperoleh dari gabungan evaluasi proses dan evalusi hasil pembelajaran.

Dengan demikian tehnik evaluasi yang dilakukan di MTS Surya Buana sudah sesuai dengan kurikulum 2013. Secara sederhana dapat kami tampilkan berupa table berikut ini :

\begin{tabular}{llll}
\hline No & Aspek yang dinilai & Tehnik Penilaian & Waktu Penilaian \\
\hline 1 & Sikap spiritual & Observasi & Pada saat penampilan \\
\hline 2 & Sikap social & Observasi & $\begin{array}{l}\text { Pada saat mengasosiasi } \\
\text { di papan tulis }\end{array}$ \\
\hline 3 & Pengetahuan & Tes Lisan & $\begin{array}{l}\text { Sebelum } \\
\text { pembelajaran }\end{array}$ \\
\hline 4 & Keterampilan & Unjuk Kerja & Waktu presentasi \\
\hline
\end{tabular}

Selain itu juga, pengajar memberikan remedial kepada siswa dengan mengunakan dengan cara yaitu :

1.) Mengajarkan kembali materi yang sama tetapi dengan cara yang berbeda

2.) Tutoring sebaya yaitu bentuk perbaikan yang diberikan oleh teman sekelasnya yang pandai, sebab adakalanya siswa lebih mudah menyerap materi pembelajarna dari teman akrabnya. Dengan demikian sudah memunculkan ciri dari kurikulum 2013 yaitu siswa berperan aktif dalam proses pembelajaran. 
3.) Remidial test, pengajar mengadakan penilaian kembali dengan soal sejenis, atau soal dengan standart yang sama. Jadi dalam hal ini peserta didik yang belum menguasai materi akan dijelaskan kembali oleh pengajar.

\section{KESIMPULAN}

Analisis pengembangan kurikulum di MTS Surya Buana dari segi visi, misi, dan tujuan memiliki kesesuaian yaitu melatih siswa untuk bersaing dalam sebuah prestasi, mendorong siswa untuk menjadi pelajar yang giat dan berwawasan luas, menyelenggarakan pendidikan yang bermutu, baik dari pembelajaran, yang dapat diaplikasikan pada akhlaqul karimah atau kepribadian siswa dalam berhubungan dengan masyarakat sekitar, serta menitikberatkan siswa sebagai pribadi yang aktif, berkeyakinan terhadap Tuhan Yang Maha Esa dan dapat berinteraksi terhadap sesama.

Kemudian kurikulum yang digunakan di MTS Surya Buana sudah sesuai dengan kurikulum 2013, sebab point-point yang ada menitikberatkan pada pembelajaran berbasis karakter dan kompetensi yang mewajibkan anak untuk aktif dalam pembelajaran sebagaimana yang tercantum dalam pengertian serta tujuan Kurikulum 2013. Adapun metode yang diterapkan terbagi menjadi metode umum dan khusus, metode umum terdiri dari toriqoh intoqoiyah, toriqoh mubasyaroh, dan Al-samiyah al-syafawiyah. Dalam pelaksanaannya guru menggunakan media beragam, dan evaluasi pembelajaran yang dilakukan mencakup 4 komponen pokok yaitu spiritual, sosial, pengetahuan, dan keterampilan.

\section{DAFTAR PUSTAKA}

Al-bantani, Azkia Muharom. 2015. "Implementasi Kurikulum 2013 Pada Pembelajaran Bahasa Arab Di Madrasah Ibtidaiyah", dalam Jurnal Arabiyat UIN Jakarta, Vol 2 No. 2 : h. $179-180$

Amri, Sofan. 2013. Pengembangan dan Model Pembelajaran Dalam Kurikulum 2013, Jakarta : Prestasi Pustaka.

Arifin, Zainal. 2014. Konsep dan Model Pengembangan Kurikulum, Bandung : Remaja Rosdakarya.

Moleong, Lexy J. 2012. Metode Penelitian Kulaitatif, Bandung : Remaja Rosdakarya.

Muhamad, Abu Bakar. 1981. Metode Khusus Pengajaran Bahasa Arab, Surabaya: Usaha Nasional.

Siskandar, 2016. Evaluasi Implementasi Kurikulum 2013 di Madrasah Aliyah, dalam Jurnal Cendekia Surakarta : Pusat Kajian Bahasa dan Budaya, Vol 10, No. 2 : h. 119

Sugiyono, 2015. Metode Penelitian Pendidikan : Pendekatan Kuantitatif, Kualitatif, Dan R $\& \mathrm{D}$, Bandung: Alfabet.

Sukardi, 2004. Metodologi Penelitian Pendidikan : Kompetensi Dan Praktiknya, Jakarta : Bumi Aksara.

Sukmadinata, Nana Syaodih. 2006. Pengembangan Kurikulum : Teori dan Praktek, Bandung : Remaja Rosdakarya.

Triwiyanto, Teguh, 2015. Manajemen Kurikulum dan Pembelajaran, Jakarta : Bumi Aksara.

Zaini, Muhammad, 2009. Pengembangan Kurikulum Konsep Implementasi Evaluasi dan Inovasi, Yogyakarta : Teras.

Zulkifli, Muhammad. 2018. "Analisis Bentuk Evaluasi Kurikulum 2013 Mata Pelajaran Bahasa Arab Di MI”, dalam Jurnal Al-Madrasah STIQ Amuntai Kalimantan Selatan, Vol. 2, No. 2 : h. 127-128 